\title{
Nonlinear Optics: A Vibrant Field
}

\author{
Mirosław A. Karpierz ${ }^{* 1}$ and George I. Stegeman ${ }^{1,2}$ \\ ${ }^{1}$ Faculty of Physics, Warsaw University of Technology, Koszykowa 75, 00-662 Warszawa \\ ${ }^{2}$ College of Optics and Photonics, Center for Research in Optics and Lasers, University of Central Florida, \\ 4000 Central Florida Blvd, Orlando FL 32816, Florida, USA
}

Received December 30, 2009; accepted December 31, 2009; published December 31, 2009

\begin{abstract}
We present here a brief history and an editorial perception of nonlinear optics.

The field of nonlinear optics has been active now for over 40 years and has richly contributed to many fields such as medicine, optics, physics, chemistry and biology to name a few. It's founding fathers have been rewarded by many honors by the science community at large, e.g. the Nobel Prize to Nicolaas Bloembergen [1,2] and by the optics, physics and chemistry communities with prizes bestowed by the Optical Society of America, SPIE etc. Hence one might think that interest in this field is finally dying off. However, the contrary is true. Although the field has matured and it is probable that most of the fundamental nonlinear interactions have been discovered by now, new ideas have continuously emerged. Classic recent examples are the interest in solitons and their dynamics, nonlinear optics in nano and meso-structured materials, etc. In many cases nonlinear optics has led to better understanding of fields such as nonlinear dynamics simply because optical experiments can be controlled and manipulated in the laboratory. A continuing trend has been the search for new and better materials which started with the inception of the field and continues vigorously today.
\end{abstract}

The history of nonlinear optic research can be backed to the year 1875, when John Kerr, lecturer in the Glasgow Free Church Teacher Training College, co-worker and friend of Lord Kelvin, discovered in glass the quadratic electro-optic effect, subsequently named after him [3]. Linear electro-optic phenomena were observed in 1893 by German physicist Friedrich Pockels [4]. The first alloptical nonlinear effect, two-photon absorption, was analysed theoretically in 1931 by Maria Goeppert-Mayer, Nobel Prize laureate in physics for discoveries concerning nuclear shell structure [5]. In 1956 Amyand D. Buckingham, professor of chemistry in University of Cambridge, published the theory of molecular orientation in strong optical field, i.e. the theory of the optical Kerr

*E-mail: karpierz@if.pw.edu.pl effect [6]. This work inspired professor Arkadiusz Piekara and his assistant Stanisław Kielich which led to the first paper on optical nonlinearity which appeared in $1958[7,8]$.

Nonlinear optical phenomena are significant for high intensities of light and therefore experimental work became possible after the development of the laser in 1960 by Theodor Maiman from Hughes Research Laboratories in Malibu [9]. One year later (in 1961) at the University of Michigan Peter A. Franken with coworkers observed in quartz crystals second harmonic generation of light from such a rubidium laser [10]. Extremely fast progress in nonlinear optics initially was connected with new effects and optimal configurations, later with applications and investigation new materials and mechanisms of nonlinearity.

Very quickly it was realized that optical waveguides, including fibers were optimal for nonlinear optics due to their confinement of light to an optical wavelength in one and two dimensions, thus producing high intensities at modest power levels for distances up to kilometers. This came as a result of the development, parallel to nonlinear optics in the 1960s of optical fibers for telecommunications, stimulated among others by Charles Kao, honored for this by the Nobel Prize in 2009 [11]. Observation of light guiding in dielectric media was initiated in the middle of the XIX'th century. In 1841 Daniel Colladon, professor at the University in Geneva, illuminated a stream of water flowing out from the tank by guiding light inside it which was subsequently scattered out by inhomogenieties in the water [12]. These initial observations were refined by a number of eminent researchers such as Tyndall and Babinet [12-14], this effect was even used in performances of the Paris Opera and was subsequently patented for the transmission of images [15-17]. In the 1960s researchers begun investigations of optical communications but losses in optical fibers in those times exceeded $1000 \mathrm{~dB} / \mathrm{km}$ making them useless for long-distance connections. However the possibility of diminishing losses was noticed by a team at the Standard Telecommunications 
Laboratories initially headed by Antoni E. Karbowiak, and later by Charles Kao [18]. The explanation that the optical fiber loss was due to impurities and the key prediction that it should be reducible below $20 \mathrm{~dB} / \mathrm{km}$ was first published in 1966 [19, 20]. Low loss fibers were drawn in the summer of 1970 at the Corning Glass Company [21] and by 1979 the losses were reduced to 0.2 $\mathrm{dB} / \mathrm{km}$ [22]. It should be noted that advantages of optical fibers was recognized very early in Poland and a conference on optical fibers and their applications was organised in 1976 in Jablonna [23].

The first experimentally observed nonlinear effect in optical waveguides was second harmonic generation [24]. This resulted from the fact that light in waveguides propagates as a set of discrete modes and its effective properties (like refractive index, dispersion, nonlinearity etc.) are a resultant of both material and geometrical factors [25]. Nonlinear optics in fibers received a large stimulus from the 1973 paper by Akira Hasegawa and Frederick Tappert in which they proposed the implementation of optical solitons in optical fibers for telecommunications [26]. Optical fibers and waveguides also enabled the observation of new phenomena not existing in bulk media, primarily due to the work of Roger Stolen and colleagues at Bell Laboratories in fibers [27].
This special issue is devoted to nonlinear optics. It's core comes from papers presented at the Xth International Workshop on Nonlinear Optics Applications in September 2009 held in Zakopane Poland. The International Workshops on Nonlinear Optics Applications have been organised since 1992 by researchers at the Warsaw University of Technology and the West Pomeranian University of Technology. They were initiated by Jan Petykiewicz and Marian Wabia and now they are organised by Ewa Weinert-Raczka with Mirosław Karpierz. The purpose of these Workshops is to provide a forum for both senior and young scientists from different countries to present and discuss current research problems. The Workshops dealt with experimental and theoretical aspects of the applications of nonlinear optics, including nonlinear guided wave optics, optical solitons, optical switching and processing, nonlinear optical materials, etc. Usually the main interest was focused on nonlinear guided wave optics, optical solitons in different media and their application for optical switching and processing. However, the workshop has dealt with a broad range of related photonic phenomena such as magnetooptic effects and optical effects in complex materials.

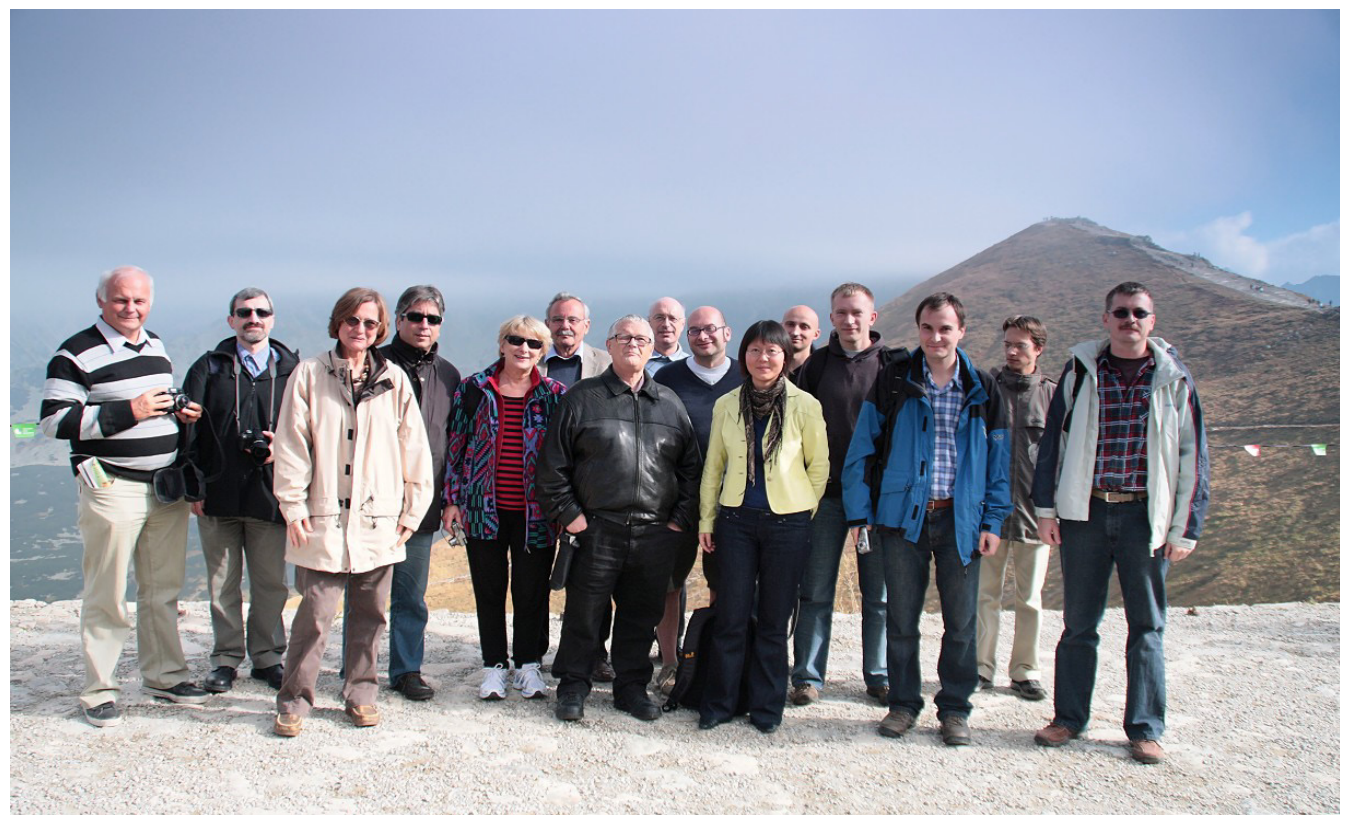

Fig. 1. Participants of the Xth International Workshop on Nonlinear Optics Applications (September 2009, Zakopane Poland) from the left: J. Jasiński, W.Bajdecki, E. Weinert-Rączka, G.Assanto, B.Jaskorzyńska, F.Lederer, G.Stegeman, N.Smyth, R.Morandotti, Y.Sheng, P.Jung, M.Kwaśny, K.Zegadło, P.Makowski, M.Karpierz 
The diversity of that work reported here in the first 12 papers covers a large spectrum of nonlinear optics. This includes research on nonlinear materials for both second and third order nonlinear optics, waveguide candidates for nonlinear optics and on various soliton phenomena with a strong focus on exciting new developments in nematic chiral and doped liquid crystals.

\section{References}

[1] N. Bloembergen, Nonlineor Optics, W.A. Benjamin 1965, $4^{\text {th }}$ Edition: World Scientific Publishing 1996.

[2] N. Bloembergen, Encounters in Nonlinear Optics, World Scientific Publishing 1996.

[3] J. Kerr: A new relation between electricity and light: Dielectrified media birefringent, Phil. Mag. 50, s. 337-348 i s. 446-458, (1875).

[4] F. Pockels: Ueber den Einfluss des elektrostatischen Feldes auf das optische Verhalten piëzoelektrischer Krystalle, Abhandlungen der Gesellschaft der Wissenschaften in Göttingen, MathematischPhysikalische Klasse 39, s. 1-204, (1894).

[5] M. Göppert-Mayer: Ueber Elementarakte mit zwei Quanenspruengen, Ann. Phys. 9, s. 273-294, (1931).

[6] A. D. Buckingham: Birefringence Resulting from the Application of an Intense Beam of Light to an Isotropic Medium, Proc. Phys. Soc. B 69, s. 344-349, (1956).

[7] A. Piekara, S. Kielich: Theory of Orientational Effects and Related Phenomena in Dielectric Liquids, J. Chem. Phys. 29, s. 1297-1305, (1958).

[8] http://zon8.physd.amu.edu.pl/

[9] T. H. Maiman: Stimulated optical radiation in ruby, Nature 187, s. 493-494, (1960).

[10] P. A. Franken, A. E. Hill, C. W. Peters, G. Weinreich: Generation of Optical Harmonics, Phys. Rev. Lett. 7, s. 118-119, (1961).

[11] Jeff Hecht, City of Light: The Story of Fiber Optics, Oxford University Press 1999; http://www.jeffhecht.com/history.html
[12] D. Colladon: Sur les réflexions d'un rayon de lumière à l'intérieur d'une veine liquide parabolique, Comptes Rendus 15 (Oct. 24), s. 800-802, (1842).

[13] J. Babinet: Note sur la transmission de la lumière par des canaux sinueux, Comptes Rendus 15 (Oct. 24), s. 802, (1842).

[14] J. Tyndall: On some Phenomena Connected with the Motion of Liquids, Proc. Roy. Inst. 1, s. 446-448, (1854).

[15] J.L. Baird: British Patent 285, 738, (1927)

[16] C.W. Hansell: Method for transferring a dial reading to a distance, U.S. Patent 1 751 584, (1930)

[17] H. Lamm: Biegsame optische gerate, Z. Instumentenk 50, s. 57981, (1930).

[18] A.E. Karbowiak, In the beginning there was light, Optoelectron. Review 3, 71-73 (1995).

[19] K.C. Kao, G.A. Hockham: Dielectric-fibre Surface Waveguides for Optical Frequencies, Proc. IEE 113, s. 1151-1158, (1966).

[20] A. Werts: Propagation de la lumiére coherente dans les fibres optiques, L'Onde. Electrique 46, s. 967-980, (1966).

[21] F. P. Kapron, D. B. Keck, R. D. Maurer: Radiation losses in glass optical waveguides, Appl. Phys. Lett. 17, s. 423-425, (1970).

[22] T. Miya, T. Terunama, T. Hosaka, T. Miyashita: Ultimate low loss single mode fibers at 1.55 pm, Electron. Lett. 15, s. 106-108, (1979).

[23] First conference was initiated by J. Groszkowski, B. Paszkowski, A. Smoliński, Z. Szpigler, and A. Waksmundzki.

[24] P.K. Tien, R. Ulrich, R.J. Martin: Optical second harmonic generation in form of coherent Cerenkov radiation from a thinfilm waveguide, Appl. Phys. Lett. 17, s. 447-450, (1970).

[25] G. I. Stegeman, C. T. Seaton: Nonlinear integrated optics, J. Appl. Phys. 58, s. R57-R77, (1985).

[26] A. Hasegawa, F. Tappert: Transmission of stationary nonlinear optical pulses in dispersive dielectric fibers, Appl. Phys. Lett. 23 , s. 142-144, (1973).

[27] R. Stolen, Recipient of the 2005 John Tyndall Award (sponsored by the Optical Society of America and the with IEEE/Lasers and Electro-Optics Society) "for fundamental contributions to the understanding of optical fiber nonlinearities". 